\title{
Influence of applied magnetic field strength and frequency response of pick-up coil on the Magnetic Barkhausen Noise profile
}

\author{
M. Vashista* and V. Moorthy \\ Design Unit, School of Mechanical and Systems Engineering, Newcastle University, \\ UK \\ *Visiting Research Fellow from the Department of Mechanical Engineering, Indian \\ Institute of Technology (B.H.U.), India
}

\begin{abstract}
The influence of applied magnetic field strength and frequency response of the pick-up coil on the shape of Magnetic Barkhausen Noise (MBN) profile have been studied. The low frequency MBN measurements have been carried out using 5 different MBN pick-up coils at two different ranges of applied magnetic field strengths on quenched \& tempered (QT) and case-carburised \& tempered (CT) $18 \mathrm{CrNiMo} 7$ steel bar samples. The MBN pick-up coils have been designed to obtain different frequency response such that the peak frequency response varies from $\sim 4 \mathrm{kHz}$ to $\sim 32 \mathrm{kHz}$ and the amplitude of low frequency signals decreases gradually. At lower applied magnetic field strength of $\pm 14000 \mathrm{~A} / \mathrm{m}$, all the pick-up coils produced a single peak MBN profile for both QT and CT sample. However, at higher applied magnetic field strength of $\pm 22000 \mathrm{~A} / \mathrm{m}$, the MBN profile showed two peaks for both QT and CT samples for pick-up coils with peak frequency response up to $\sim 17 \mathrm{kHz}$. Also, there is systematic reduction in peak 2 for QT sample and asymmetric reduction in the heights of peak 1 and peak 2 for CT sample with increase in peak frequency response of the pick-up coils. The decreasing sensitivity of pick-up coils with increasing peak frequency response to MBN signal generation is indicated by the gradual reduction in width of MBN profile and height of peak 2 in QT sample. The drastic reduction in peak 1 as compared to peak 2 in CT sample shows the effect of decreasing low frequency response of the pick-up coils on lowering skindepth of MBN signal detection. This study clearly suggests that it is essential to optimise both maximum applied magnetic field strength and frequency response of the MBN pick-up coil for maximising the shape of the MBN profile for appropriate correlation with the magnetisation process and hence the material properties.
\end{abstract}

Keywords: Magnetic Barkhausen noise, frequency spectrum, gear steel, carburised steel, tempered steel.

\section{Introduction:}

When a ferromagnetic material is subjected to an external varying magnetic field, a voltage signal is induced in a pick-up coil due to changes in magnetisation of material caused by the discrete movement of magnetic domain walls overcoming various pinning sites in the material [1]. This phenomenon of electromagnetic activity known as Magnetic Barkhausen noise (MBN) signal generation can have a wide frequency spectrum depending on the rate of change of magnetic flux at the micro and macro level of magnetisation process inside the ferromagnetic 
This article is author's version published in the Journal of Magnetism and Magnetic Materials, 345 (2013) 208-214. Final published version of this paper is available at

http://dx.doi.org/10.1016/j.jmmm.2013.06.038

material. The frequency of discrete magnetisation changes is believed to range starting from an order of the excitation frequency of the applied magnetic field and spreads beyond $1 \mathrm{MHz}$ in most ferromagnetic materials. Since the MBN signals are the voltage pulses induced by the changing discrete magnetic flux on to a pick-up coil placed on the surface of a test material, it is believed that the detected MBN signal will reflect more of the characteristics of the pick-up coil than that of the actual rate of change of micro-magnetisation process inside the material which is an unknown factor. However, the strength of induced voltage pulses is expected to decay exponentially as a function of depth under homogeneous excitation of magnetic field due to eddy current damping experienced by the propagating electromagnetic fields created by the movement of magnetic domain walls. The extent of damping determines the detectiondepth (skin-depth) of MBN signals. The main factors affecting the skin-depth of electromagnetic signals are frequency of the signal, conductivity and permeability of the material [1-3]. Jiles and Suominen [3] while working on assessment of micro-hardness and residual stress observed that the skin-depth of $\mathrm{MBN}$ at the same analyzing frequency decreases for materials having higher specific electric conductivity and relative permeability.

The determination of skin-depth of MBN signals is more complicated than skin-depth of eddy current due to generation of MBN signals in wide frequency range. It has also been observed that the detection depth of MBN signal also depends on applied magnetic field strength \& its excitation frequency, sensitivity \& frequency response of the MBN pickup coil, analyzing frequency range of the MBN signal [4]. Studies from literature shows that various MBN signal parameters are used for microstructural characterization [5,6], assessment of residual stress [7], plastic deformation [8,9] and fatigue [9-12]. A handful of researchers [13,14] attempted filtering of frequency spectrum of MBN signal in various band-widths to characterize casedepth of case-hardened steel. Dubois and Fiset [13] evaluated case-depth in carburized steels by using frequency spectrum obtained at various frequency ranges, each $20 \mathrm{kHz}$ band-widths, from 0 to $200 \mathrm{kHz}$. It has also been shown that the low frequency MBN measurements distinctly show the MBN signals from near-surface hardened layer and that from deep subsurface softer layers as two well-defined MBN peaks [15,16].

It is realised that pick-up coil with wide frequency bandwidth will have poor sensitivity due to less number of turns and may not help in detecting MBN signals generated from magnetisation process in the deep subsurface. This will result in shallow skin-depth for this technique.

It is known that the MBN pick-up coil can have different frequency response depending on the number of turns and coil diameter. Different pick-up coils are expected to have resonance behaviour at some characteristic frequency depending on the coil impedance. However, they 
This article is author's version published in the Journal of Magnetism and Magnetic Materials, 345 (2013) 208-214. Final published version of this paper is available at

http://dx.doi.org/10.1016/j.jmmm.2013.06.038

will possess significant sensitivity at frequencies close its resonant frequency. It is expected that the synergistic effect of a characteristic frequency response of the pick-up coil and a specific range of rate of change of magnetisation process can change the shape of the MBN profile. Hence, an optimum combination of a characteristic pick-up coil and maximum magnetic field strength \& its excitation frequency will help in obtaining the best possible MBN profile with maximum details about the magnetisation process in a material condition. In spite of various studies in the literature on MBN measurements, the influence of characteristic frequency response of the pick-up coils and the applied magnetic field strength on the shape of the MBN signal profile is not discussed in detail. However, it has been observed that the MBN profile can show a single peak or multiple peaks depending on the microstructural state in the material.

The present study has been aimed at understanding the influence of frequency response of different pick-up coils and maximum applied magnetic field strengths on the low frequency MBN profile in $18 \mathrm{CrNiMo7}$ steel samples with two different material conditions.

\section{Experimental:}

Rectangular bar specimens having $12 \times 10 \times 135 \mathrm{~mm}^{3}$ were prepared from the widely used $18 \mathrm{CrNiMo} 7$ grade gear steel for this study. The chemical composition of the steel is given below in Table 1. The bar samples were solutionised at $930^{\circ} \mathrm{C}$ for $1 \mathrm{~h}$ followed by oil quenching and tempered at $180^{\circ} \mathrm{C}$ for $2 \mathrm{hrs}$. Some of the samples were case-carburized at $930^{\circ} \mathrm{C}$ to a case-depth of $\sim 1 \mathrm{~mm}$ and tempered at $180^{\circ} \mathrm{C}$ for $2 \mathrm{hr}$. Specimens were carefully surface ground to remove surface oxidation and grain boundary oxidation layers. The low frequency MBN measurements were made using a laboratory based MBN system developed at Newcastle University, UK. The details of the MBN system and measurement procedure are given elsewhere [4].

Table 1: Chemical composition of the steel used in this study

\begin{tabular}{|c|c|c|c|c|c|c|c|c|c|c|c|c|c|}
\hline Steel & $\mathrm{C}$ & $\mathrm{Mn}$ & $\mathrm{Si}$ & $\mathrm{P}$ & $\mathrm{S}$ & $\mathrm{Cr}$ & $\mathrm{Ni}$ & $\mathrm{Mo}$ & $\mathrm{V}$ & $\mathrm{Cu}$ & $\mathrm{Al}$ & $\mathrm{Sn}$ & $\mathrm{Fe}$ \\
\hline 18CrNiMo7-6 & 0.195 & 0.54 & 0.19 & 0.009 & 0.026 & 1.58 & 1.52 & 0.3 & 0.005 & 0.15 & 0.032 & 0.018 & Bal. \\
\hline
\end{tabular}


This article is author's version published in the Journal of Magnetism and Magnetic Materials, 345 (2013) 208-214. Final published version of this paper is available at

http://dx.doi.org/10.1016/j.jmmm.2013.06.038

The quenched \& tempered (QT) and carburised \& tempered (CT) bar samples were subjected to an alternating magnetic field excitation at $0.4 \mathrm{~Hz}$ with a triangular waveform voltage of \pm 20 $\mathrm{V}$ using two different U-shaped iron-core electromagnetic yokes having different number of turns. The yoke $\mathrm{Y} 1$ can generate a maximum applied magnetic field strength $\left(\mathrm{H}_{\mathrm{amax}}\right)$ of \pm 14000 $\mathrm{A} / \mathrm{m}$. The yoke $\mathrm{Y} 2$ can generate a $\mathrm{H}_{\mathrm{amax}}$ of $\pm 22000 \mathrm{~A} / \mathrm{m}$. The MBN signals were acquired with five different ferrite cored pick-up coils identified as L2, L1, S2, S1 and S4 having different number of turns such that the number of turns in $\mathrm{L} 2>\mathrm{L} 1>\mathrm{S} 2>\mathrm{S} 1>\mathrm{S} 4$. The MBN signals were acquired after filtering using $1 \mathrm{kHz}$ high-pass filter and amplification to $60 \mathrm{~dB}$ for QT sample and to $72 \mathrm{~dB}$ for $\mathrm{CT}$ sample. The MBN signal and the magnetic excitation voltage were acquired using a NI PCI-6111 data acquisition card using a LabVIEW program. Since the MBN signals were acquired over 4 cycles of magnetisation (10s duration) for averaging, the sampling rate of data acquisition was limited to $200 \mathrm{kHz}$ per channel for optimum memory size of the card, which is sufficient for appropriate sampling of signals up to $\sim 50 \mathrm{kHz}$. Typical magnetic excitation voltage and the MBN signal are shown in Fig. 1 over a period of 10s (4 cycles of magnetisation). The average rms voltage profile of the MBN signal over 4 excitation cycles has been determined. Since triangular waveform excitation is used, the excitation voltage $(\mathrm{V})$ can be linearly related to the applied magnetic field strength $\left(\mathrm{H}_{\mathrm{a}}\right)$ for each yoke and hence, it can be used as an independent parameter for easy representation. It is important to note that the excitation voltage of $\pm 20 \mathrm{~V}$ corresponds to $\pm 14000 \mathrm{~A} / \mathrm{m}$ for yoke $\mathrm{Y} 1$ and \pm 22000 $\mathrm{A} / \mathrm{m}$ for yoke $\mathrm{Y} 2$. Hence, the yoke $\mathrm{Y} 1$ is expected to induce cyclic magnetisation process over a smaller range than the yoke $Y 2$. However, since the low frequency MBN profile is shown as a plot of average rms voltage of the MBN signal as a function of excitation voltage (V) applied to the electromagnetic yoke, the MBN profiles obtained with yoke $\mathrm{Y} 1$ appear broader than that with yoke $Y 2$. This is due to lower maximum applied magnetic field strength in $Y 1$ than in $Y 2$ induced by the same excitation voltage of $\pm 20 \mathrm{~V}$. The frequency spectrum of the MBN signals induced as voltage pulses in the pick-up coil has been determined from the Fast Fourier Transformation (FFT) of the time-domain signals using MATLAB. 


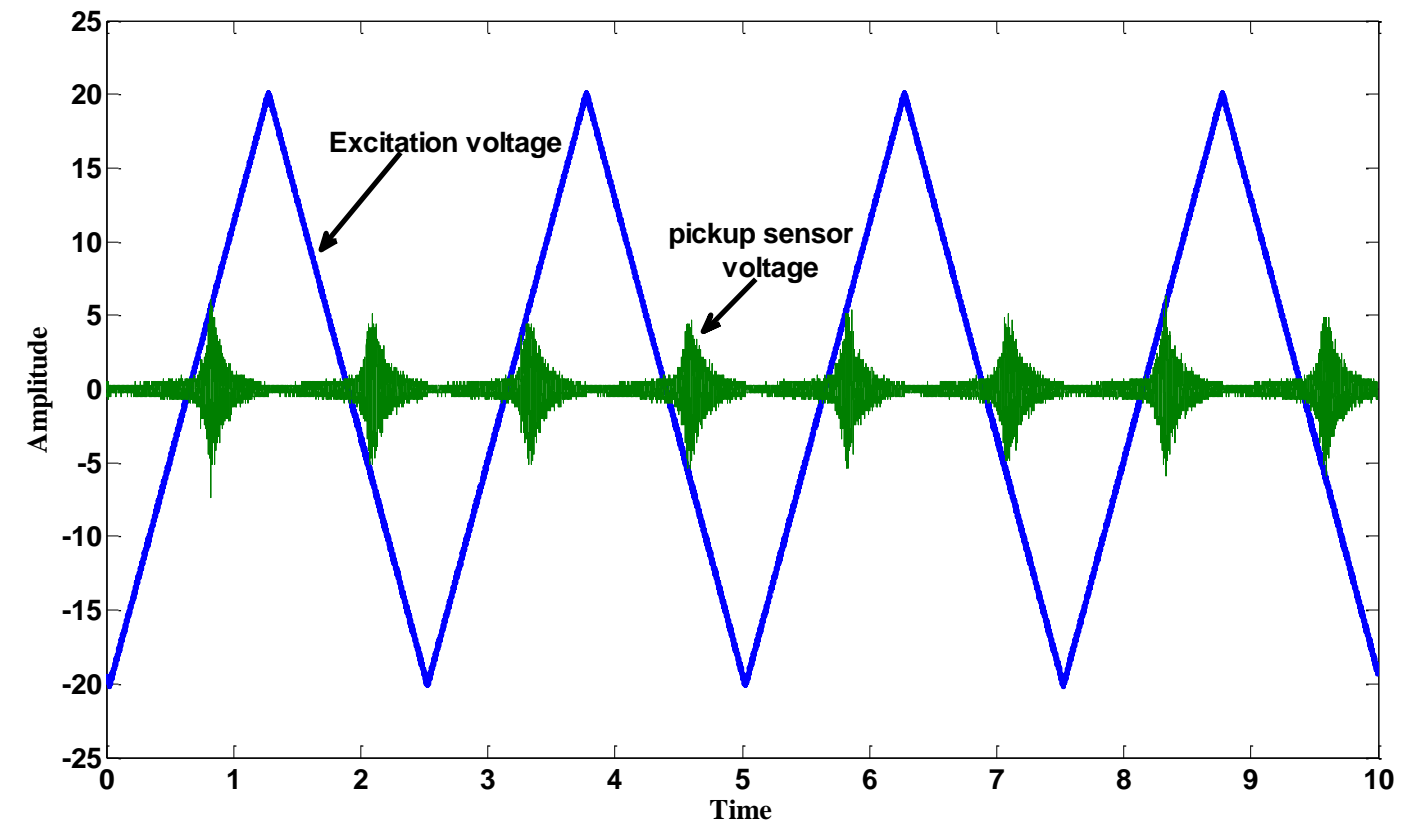

Fig.1. Typical excitation voltage and the MBN signals in time domain

\section{Results and discussion}

The characteristic shape of MBN profiles obtained using different electromagnetic yokes and pick-up coils in QT and CT samples and their correlation to characteristic frequency response of each pick-up coil are shown and discussed below.

\subsection{MBN profiles for different pick-up coils}

The low frequency MBN profiles obtained with different pick-up coils using electromagnetic yokes $\mathrm{Y} 1$ and $\mathrm{Y} 2$ in quenched and tempered (QT) are shown in Fig.2(a-b). It can be found from Fig.2(a-b) that all the MBN profiles show single peak for yoke $\mathrm{Y} 1$ with lower $\mathrm{H}_{\mathrm{amax}}$ whereas the MBN profiles show a slope change indicating the presence of peak 2 at higher excitation voltage ( 8V) for yoke Y2 with higher $\mathrm{H}_{\text {amax. }}$ Such two-peak MBN profile has been observed earlier in tempered ferritic steels and the peak at lower field is attributed to the movement of domains walls overcoming lath / grain boundaries and the peak at higher field is attributed to the movement of domains walls overcoming carbide precipitates $[5,6]$.

The quenched and tempered sample does not have any gradient in composition or microstructure across the depth. Hence, it is expected that the frequency response of the pickup coil will not have very significant effect on the shape of the MBN profile since the MBN signals are generated over wide frequency range. However, the maximum applied magnetic 
This article is author's version published in the Journal of Magnetism and Magnetic Materials, 345 (2013) 208-214. Final published version of this paper is available at

http://dx.doi.org/10.1016/j.jmmm.2013.06.038

field strength can greatly influence the extent of magnetisation in the material and hence the shape of the MBN profile. With lower $\mathrm{H}_{\text {amax }}$ in yoke $\mathrm{Y} 1$, the second MBN peak could not be detected due to insufficient magnetic field strength for domain walls to overcome carbide precipitates. With higher $\mathrm{H}_{\text {amax }}$ in yoke $\mathrm{Y} 2$, the magnetic field is strong enough for the domain walls to overcome carbide precipitates and hence the MBN profile shows peak 2 at higher excitation field (Fig.2(b)).

It can be observed from Fig.2(a) that the variation in peak 1 height at lower excitation voltage among different pick-up coils is about $\sim 10 \%$ and is not showing any systematic trend. However, the width of MBN profile is highest for $L 2$ and it decreases for $L 1$ and remains more or less the same for S2, S1 and S4. It can be observed from Fig.2(b) that the peak 2 at higher excitation voltage shows maximum height for L2 and decreases for L1, S2, S1 and S4 to a lower extent.

The low frequency MBN profiles obtained with different pick-up coils using electromagnetic yokes $\mathrm{Y} 1$ and $\mathrm{Y} 2$ in carburised and tempered (CT) samples are shown in Fig.3(a-b). It can be found that all the MBN profiles show single peak for yoke Y1 (Fig.3(a)) whereas the MBN profiles show two peaks for yoke Y2 except for pick-up coil S4 (Fig.3(b)). Typically, the carburised steel will have higher carbon content and hardness near the surface up to a depth of $\sim 300 \mu \mathrm{m}$ and then they gradually decreases over a depth to reach a constant value of core matrix. Hence, the carburised region can be considered to consist of two layers, one hard region near the surface and a relatively softer subsurface region. The two layers are expected to undergo magnetisation in different magnetic field ranges. With yoke $\mathrm{Y} 1$, the maximum magnetic field strength is not sufficient enough to induce strong magnetisation of hard nearsurface case region to generate distinct second MBN peak. The single peak is mainly due to magnetisation of relatively softer subsurface region with lower carbon content after carburisation. However, the broader MBN profile (Fig.3(a)) as compared to non-carburised QT sample (Fig.2(a)) suggests that the magnetisation from harder carburised near-surface may also contribute to a smaller extent at higher field (excitation voltage $>10 \mathrm{~V}$ ). The higher MBN peak position ( 8V in Fig.3(a)) as compared to non-carburised QT sample ( 6V in Fig.2(a)) suggests that the MBN signal is contributed mainly by the magnetisation of the subsurface region with lower carbon content and to a lesser extent by the magnetisation of the surface region with high carbon content. Due to lower applied magnetic field strength $\mathrm{H}_{\mathrm{amax}}$ in yoke $\mathrm{Y} 1$, the magnetisation of harder surface and that of softer subsurface regions are superimposed resulting in a broader single peak MBN profile (Fig.2(a)). 
This article is author's version published in the Journal of Magnetism and Magnetic Materials, 345

(2013) 208-214. Final published version of this paper is available at

http://dx.doi.org/10.1016/j.jmmm.2013.06.038

With yoke Y2, the maximum applied magnetic field strength is sufficient enough to induce strong magnetisation of hard near-surface region to generate MBN peak 2 at higher excitation voltage. Such two-peak MBN profiles have been observed earlier in case hardened steels $[15,16]$. In case of carburised steel, the peak 1 at lower field is attributed to the movement of domains walls in softer region in the subsurface ( $>300 \mu \mathrm{m}$ depth) and the peak 2 at higher field is attributed to the movement of domains walls in the harder region near the surface $(<300$ $\mu \mathrm{m}$ depth) [16].

It can be found in CT sample that, unlike the QT sample, even with electromagnetic yoke $Y 1$, the height of single peak shows maximum value for pick-up coil L2 and then decreases for L1, $\mathrm{S} 2, \mathrm{~S} 1$ and S4. For yoke $\mathrm{Y} 2$, the peak 1 at lower excitation voltage decreases more rapidly as compared to peak 2 at higher excitation voltage and also, the peak 1 is not well defined for pick-up coil S4. Since the carburised steel sample has sharp gradient in carbon content and hardness level along the depth direction, it is expected that the low frequency MBN profile will change depending on the applied magnetic field strength and frequency response of the pickup due to their influence on the skin-depth of the MBN signal. The frequency response of the pick-up coil will have greater influence in detecting MBN signals corresponding to the magnetisation in deeper subsurface region due to the effect of electromagnetic attenuation of signals. Hence, it becomes important to understand the influence of frequency response of the MBN pick-up coils for correlating the variation in the shape of MBN profile in casehardened steels. 
This article is author's version published in the Journal of Magnetism and Magnetic Materials, 345 (2013) 208-214. Final published version of this paper is available at

http://dx.doi.org/10.1016/j.jmmm.2013.06.038
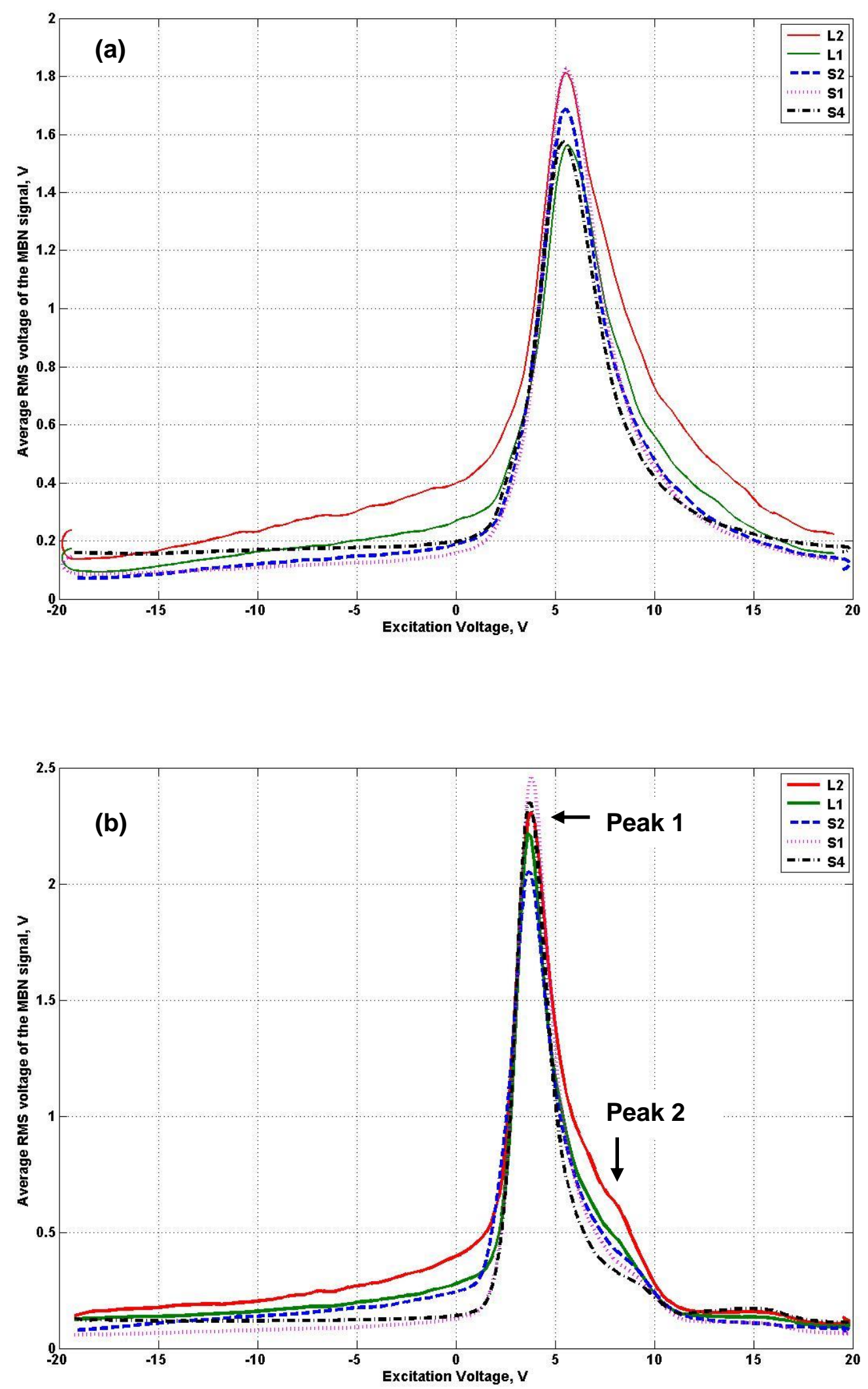

Fig.2. The low frequency MBN profiles obtained in quenched and tempered (QT) with different pick-up coils using electromagnetic yokes (a) Y1 and (b) Y2. 
This article is author's version published in the Journal of Magnetism and Magnetic Materials, 345 (2013) 208-214. Final published version of this paper is available at

http://dx.doi.org/10.1016/j.jmmm.2013.06.038
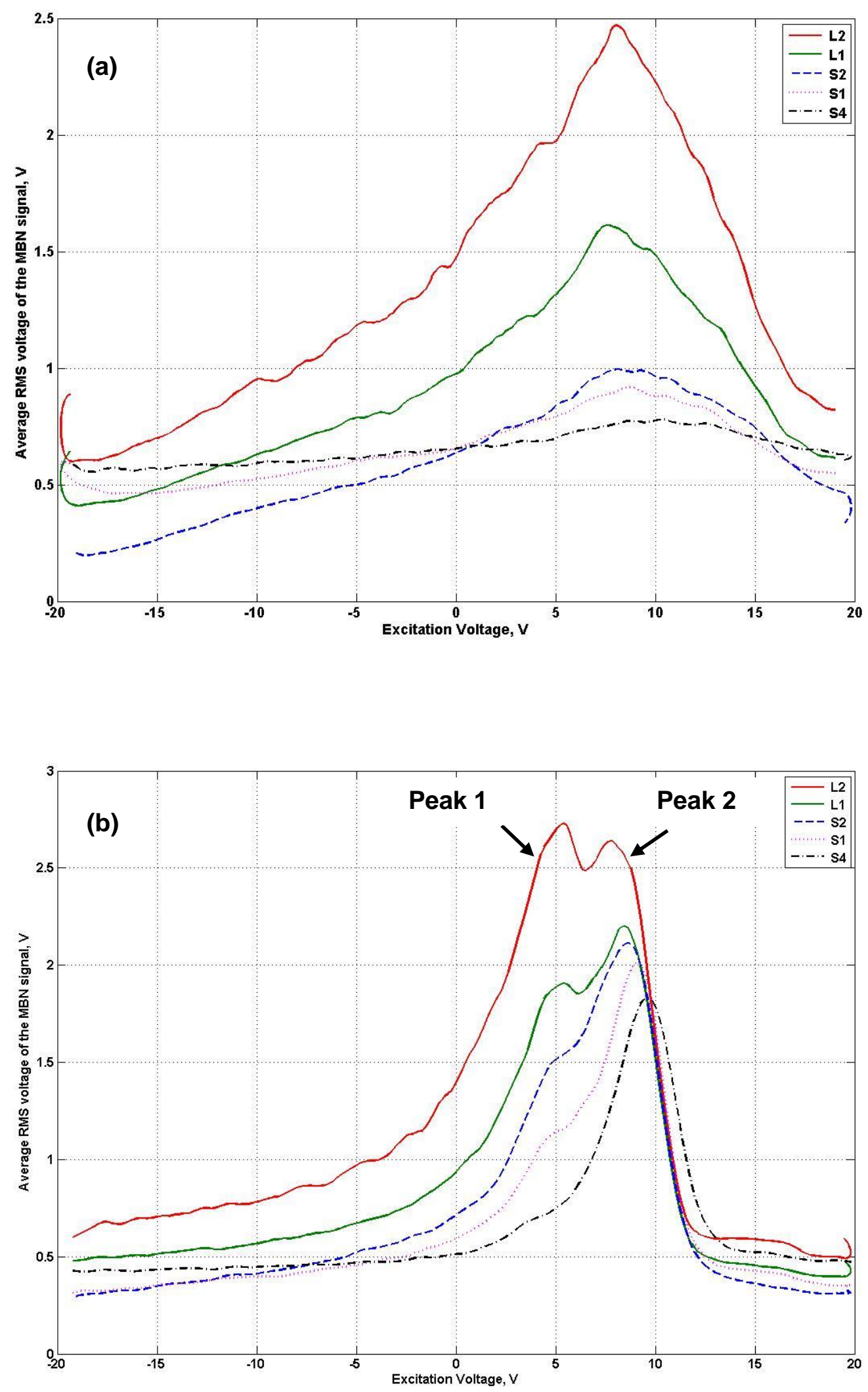

Fig.3. The low frequency MBN profiles obtained in carburised and tempered (CT) with different pick-up coils using electromagnetic yokes (a) Y1 and (b) Y2. 
This article is author's version published in the Journal of Magnetism and Magnetic Materials, 345 (2013) 208-214. Final published version of this paper is available at

http://dx.doi.org/10.1016/j.jmmm.2013.06.038

\subsection{Frequency response of different MBN pick-up coils}

The frequency spectra of the MBN signals acquired using different MBN pick-up coils in a quenched and tempered (QT) sample using the electromagnetic yoke Y2 are shown in Fig.4(ae). The $X$-axis, frequency is limited to $50 \mathrm{kHz}$, since there is no dominant frequency above 45 $\mathrm{kHz}$ for these pick-up coils. The $\mathrm{Y}$-axis, amplitude is normalised with respect to total number of samples. It can be found that the peak frequency systematically increases from $\sim 4 \mathrm{kHz}$ for pick-up coil L2 to $\sim 32 \mathrm{kHz}$ for pick-up coil S4. This is attributed to the variations in the impedance of the pick-up coils and hence their characteristic frequency response. It could also worth to verify this further by measuring impedance resonance curves of these pick-up coils which will be done in future. It can also be observed from Fig.4(a-e) that the signal amplitude in the low frequency range and that of peak frequency gradually decrease from L2 to S4. This is attributed to the varying sensitivity of the pick-up coils to the induced voltage level due to varying number of turns. The approximate values of peak frequency and the maximum frequency at $-10 \mathrm{~dB}$ level are shown below in Table 2 for different pick-up coils.

Table 2: Approximate values of peak frequency and maximum frequency at $-10 \mathrm{~dB}$ level for different MBN pick-up coils.

\begin{tabular}{|c|c|c|}
\hline MBN pick-up coil & $\begin{array}{c}\text { Peak frequency of } \\
\text { MBN signal, } \mathrm{kHz}\end{array}$ & $\begin{array}{c}\text { Maximum frequency at } \\
-10 \mathrm{~dB}, \mathrm{kHz}\end{array}$ \\
\hline L2 & 4 & 8 \\
\hline L1 & 8 & 12 \\
\hline S2 & 11 & 17 \\
\hline S1 & 16 & 23 \\
\hline S4 & 32 & 40 \\
\hline
\end{tabular}

The frequency spectra of MBN signals obtained with pick-up coil S2 from a QT sample with yokes $\mathrm{Y} 1$ and $\mathrm{Y} 2$ are shown in Fig.5(a-b). Similarly, the frequency spectra of MBN signals obtained with pick-up coil L1 from QT and CT samples with yoke Y2 are shown in Fig.6(a-b). It can be observed from Figs. 5(a-b) and 6(a-b) that the frequency response of a pick-up coil does not change significantly either with maximum magnetising field strength or with different microstructure of test material. This clearly suggests that the frequency response is mainly a characteristic of the pick-up coil. Only the induced voltage level of MBN signal is influenced 
This article is author's version published in the Journal of Magnetism and Magnetic Materials, 345

(2013) 208-214. Final published version of this paper is available at

http://dx.doi.org/10.1016/j.jmmm.2013.06.038

by the external magnetic field strength, microstructure of the test material and signal amplification (Fig.2(a-b) and 3(a-b)).

It can be observed from Fig.5(a-b) that the frequency spectrum of MBN signals generated over different ranges of magnetisation does not change significantly. It can also be observed from Fig.6(a-b) that the pick-up coil generates MBN signals in its own characteristic frequency range almost independent of the microstructure of test material. This clearly suggest that the frequency response of a pick-up coil will strongly influence the maximum depth over which the changes in magnetisation are detected as MBN signals. A pick-up coil with dominant low frequency response will have greater skin-depth of detection while a pick-up coil with more high frequency response will have shallow skin-depth. This is clearly reflected by the shape of the MBN profiles shown in Fig.2(a-b) and Fig.3(a-b).

Since the MBN signal generated in the material is attenuated by the electromagnetic eddy current opposition to an extent that depends on the frequency of the signal, the measurement depth (skin-depth) is limited to finite depth from the surface. The electromagnetic skin depth $\delta$ is given by the relation

$$
\delta=1 / \sqrt{ }\left(\pi f \sigma \mu_{\circ} \mu_{\mathrm{r}}\right)
$$

Where $f$ is the frequency of the signal, $\sigma$ is the conductivity of the material, $\mu_{0}$ is the permeability of vacuum and $\mu_{r}$ is the relative permeability of the material. Based on this equation, the MBN signals generated by a pick-up coil correspond to a skin-depth decided by the dominant frequency range of the pick-up coil, the relative permeability and conductivity of the test material. In the present study, due to higher carbon content and hardness, the CT sample will have lower permeability and conductivity values than QT sample. Hence, the skin-depth of MBN for all the pick-up coils will be higher for CT sample than QT sample. 
This article is author's version published in the Journal of Magnetism and Magnetic Materials, 345 (2013) 208-214. Final published version of this paper is available at

http://dx.doi.org/10.1016/j.jmmm.2013.06.038
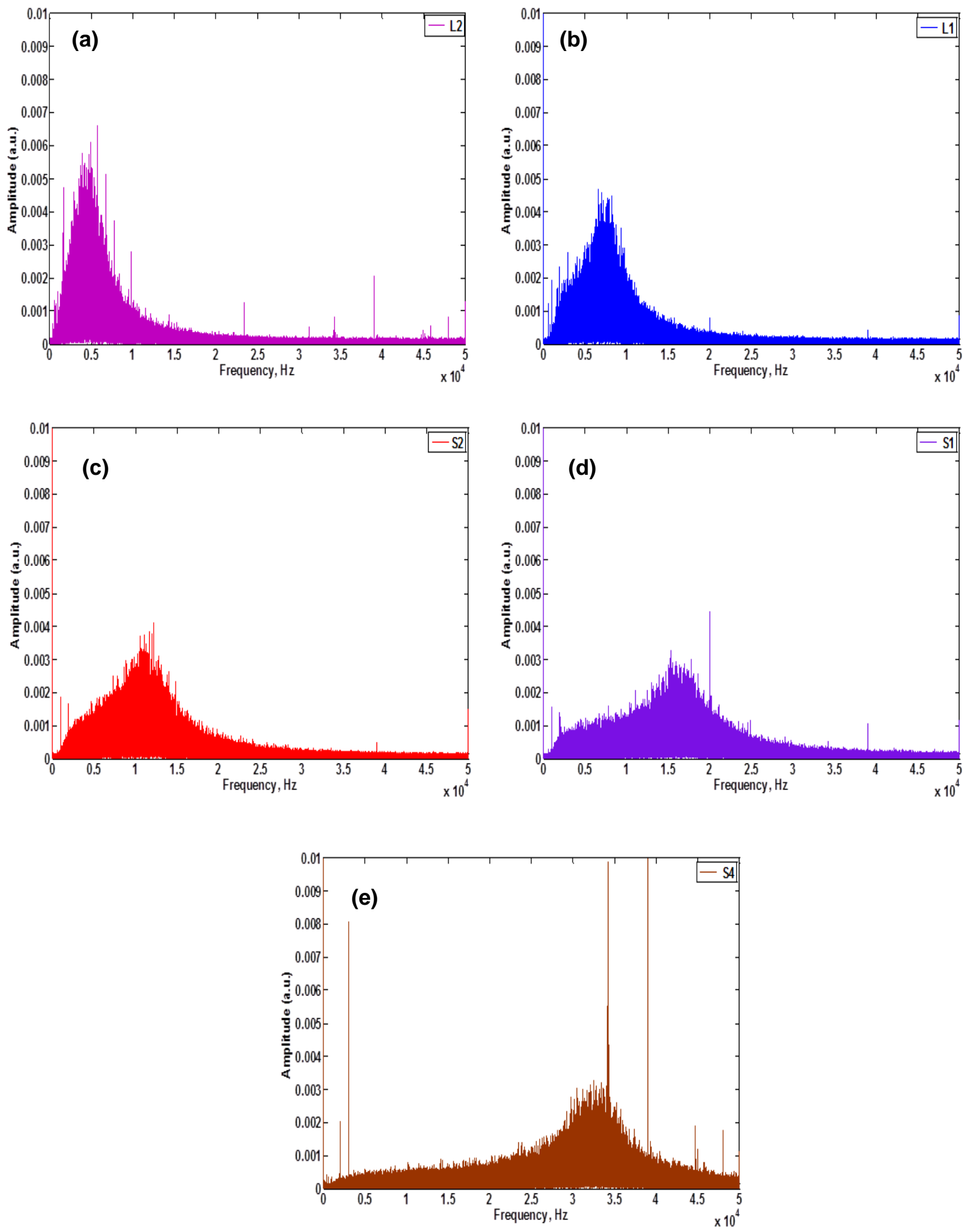

Fig. 4. Frequency spectra of MBN signals acquired using different pick-up coils in a quenched and tempered sample with electromagnetic yoke Y2. (a) L2, (b) L1, (c) S2, (d) S1 and (e) S4. 

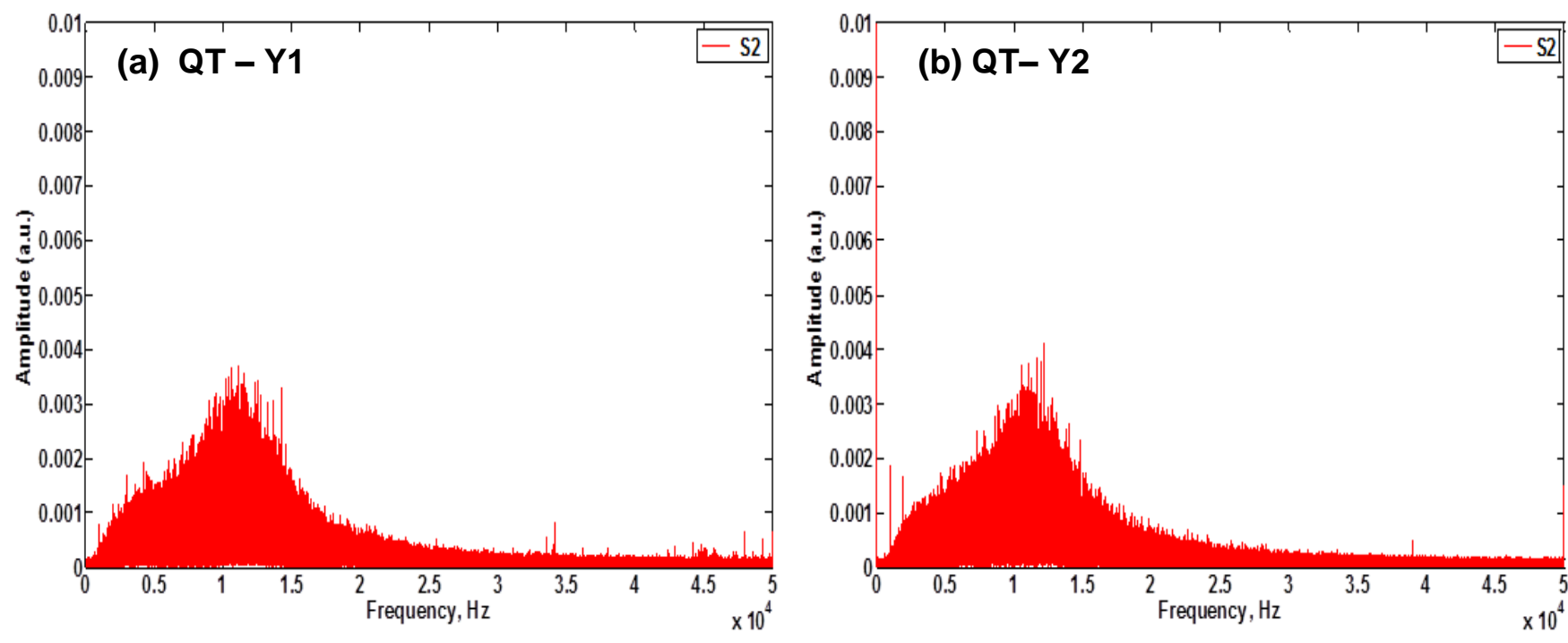

Fig. 5. Frequency spectra of MBN signals acquired using the pick-up coil S2 in a quenched and tempered sample with electromagnetic yokes (a) Y1 and (b) Y2.
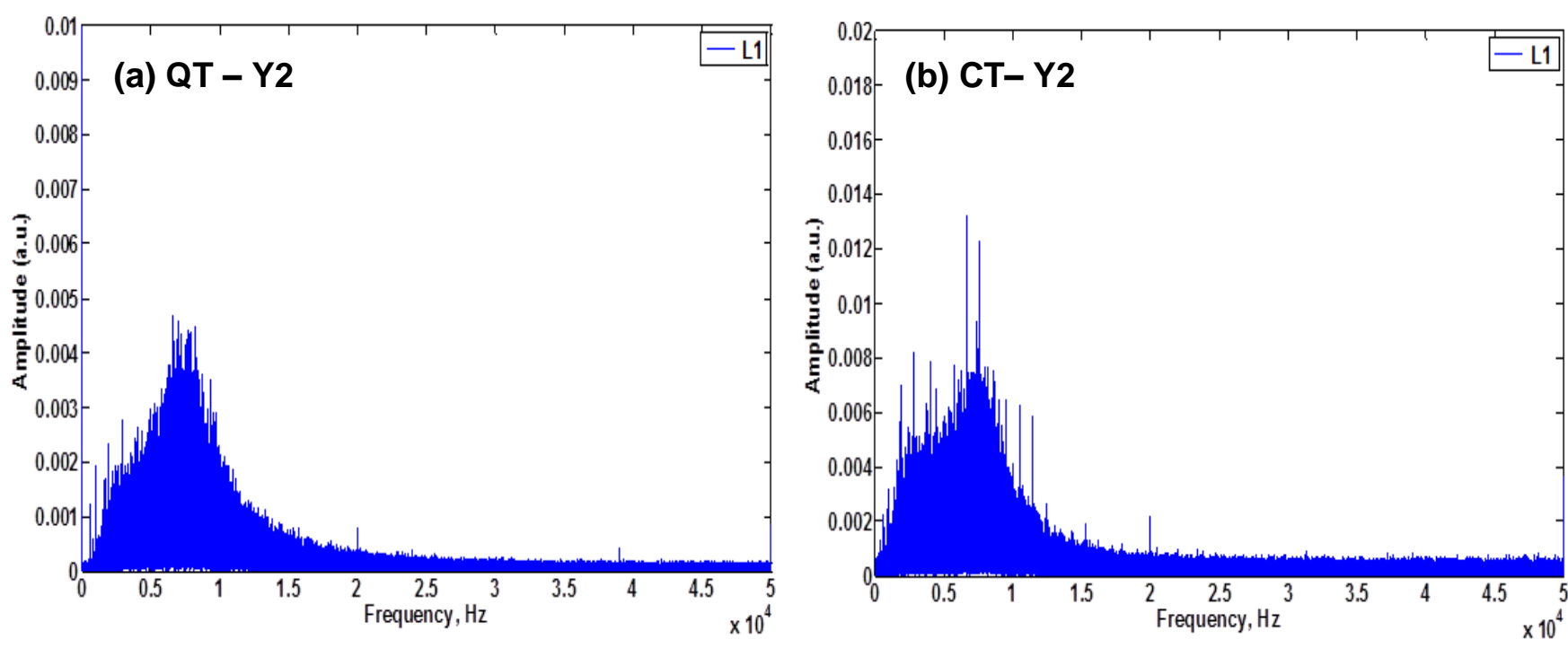

Fig.6. Frequency spectra of MBN signals acquired using pick-up coil L1 with electromagnetic yoke $Y 2$ in (a) quenched and tempered sample and (b) carburised and tempered sample.

\subsection{Correlation of shape of MBN profiles}

It can observed from Fig.4(a-e) that, even though the peak frequency response vary significantly for different pick-up coils, the area under the amplitude - frequency spectrum looks more or less similar for all the MBN pick-up coils which is considered as one of the reason for 
This article is author's version published in the Journal of Magnetism and Magnetic Materials, 345 (2013) 208-214. Final published version of this paper is available at

http://dx.doi.org/10.1016/j.jmmm.2013.06.038

similar MBN peak height for the profiles obtained with different pick-up coils in QT sample (Fig.2(a-b)).This supports that fact that the MBN signals are generated over a wide range of frequencies. In addition, since the QT sample does not have any depth gradient in material properties, the MBN profile is expected to have similar shape for all the pick-up coils as along as the sensitivity of pick-up coil is sufficient. However, when the pick-up coil has higher response in lower frequency range, the increase in skin-depth of MBN signals can contribute to more MBN signals over the entire range of magnetisation which is reflected as wider MBN profile for L2 as compared to that for L1 (Fig.2(a)). This effect is even more pronounced when combined with higher magnetic field strength as can be observed from Fig.2(b) where the second peak at higher excitation voltage is more clearly shown by pick-up coils with better low frequency response. The rate of change of magnetisation and microstructure of the material may have some subtle effect on the frequency spectrum of the MBN signals which is not well understood. However, when the applied magnetic field strength is very low, it will drastically reduce the magnetisation range. Similarly, when the peak frequency response of the pick-up coil is in very high frequency range, for example $>100 \mathrm{kHz}$, the sensitivity of the pick-up coil will be affected. Hence, both very low magnetic field strength and very high frequency response of the pick-up coil will significantly reduce the MBN peak height and hence the low frequency MBN profile.

In case of CT sample with depth gradient in carbon content and hardness, the effect of frequency response of the pick-up coils is well pronounced in addition to the effect of applied magnetic field strength (Fig.3(a-b)). The effect of decreasing response of pick-up coils in low frequency range reduces the overall width of MBN signal profile (Fig.3(a-b)) and this effect leads to faster reduction in peak 1 at lower excitation field (Fig.3(b)). The reduction in amplitude of the peak frequency for pick-up coils with increasing high frequency response results in gradual decrease in peak height in MBN profiles obtained with yoke 1 and in peak 2 at higher excitation field in MBN profiles obtained with yoke 2 . The systematic changes in the low frequency MBN profiles clearly support that fact that the lowering response of pick-up coil in low frequency range will result in smaller skin-depth of MBN signals. It is also evident from Fig.4(a-e) that the high frequency signals are more attenuated by the eddy current damping resulting in reduction of amplitude of peak frequency which in-turn leads to reduction in skindepth of MBN signals and hence the MBN peaks. It becomes obvious that the low frequency MBN profile is strongly influenced by the combined effect of decreasing sensitivity of pick-up coils with increasing high frequency response and insufficient magnetising field strength to fully magnetise the case-hardened region. 


\section{Conclusions:}

This study clearly shows that the maximum applied magnetic field strength and the frequency response of the pick-up coil have strong influence on the shape of the low frequency MBN profile.

It has been shown that, lower maximum applied magnetic field strength of $\pm 14000 \mathrm{~A} / \mathrm{m}$ produces single peak MBN profile in both quenched \& tempered (QT) and carburised \& tempered (CT) samples due to smaller range of magnetisation. Higher maximum applied magnetic field strength of $\pm 22000 \mathrm{~A} / \mathrm{m}$ produces double peak MBN profile in both QT and CT samples due to extended range of magnetisation.

The lowering response of the pick-up coils in low frequency range and shifting of peak response to higher frequencies results in narrowing down of width and reduction in peak 2 of the MBN profile in QT sample and faster reduction of the MBN peak 1 than peak 2 in case of case-hardened (CT) sample. This is attributed to the effect of lowering skin-depth of MBN signal detection for pick-up coils with more high frequency response.

This study clearly shows the importance of using optimum combination of pick-up coil sensitivity and applied magnetic field strength to maximise the shape of MBN profile and hence the potential of the MBN technique for effectively characterising microstructural conditions and case-depth of case-hardened ferritic steel components.

The relation between characteristic frequency response of the MBN pick-up coils and their impedance resonance behaviour will be established by measuring impedance resonance curves of these pick-up coils in future studies.

\section{Acknowledgements}

One of the authors (M. Vashista) wishes to show gratitude to the Department of Science and Technology, Government of India for BOYSCAST Fellowship award and Banaras Hindu University for granting him study leave for the period when this study was carried out. The authors acknowledge the support given by Dr. B.A. Shaw, Director, Design Unit, Newcastle University, UK during this study. 
This article is author's version published in the Journal of Magnetism and Magnetic Materials, 345 (2013) 208-214. Final published version of this paper is available at

http://dx.doi.org/10.1016/j.jmmm.2013.06.038

\section{References:}

1. Chikazumi S. Physics of magnetism. New York: Wiley; 1964.

2. Tiitto S., Säynäjäkangas S., Spectral Damping in Barkhausen Noise, IEEE Trans. on Magnetics 11(6), (1975) 1666-1672.

3. Jiles D. C., L. Suominen, Effect of surface stress on Barkhausen effect emissions: model prediction and comparison with $\mathrm{x}$-ray diffraction studies, IEEE trans. Magnetics. 30(6), (1994) 4764- 4766.

4. V. Moorthy, B.A. Shaw and P. Hopkins, Surface and subsurface stress evaluation in case-carburised steel using high and low frequency magnetic Barkhausen emission measurements, J. Magnetism and Magnetic Materials, 299, 2006, 362-375.

5. V. Moorthy, S. Vaidyanathan, T.Jayakumar and B. Raj, Microstructural characterization of quenched and tempered $0.2 \%$ carbon steel using magnetic Barkhausen noise analysis, Journal of Magnetism and Magnetic Materials 171 (1997) 179-189.

6. V. Moorthy, S.Vaidyanathan, T. Jayakumar and Baldev Raj, "On the influence of tempered Microstructures on magnetic Barkhausen emission in ferritic steels", Philosophical Magazine A, Vol. 77, No. 6, 1998, pp. 1499-1514.

7. Moorthy V., Shaw B.A., Mountford P. , Hopkins P., Magnetic Barkhausen emission technique for evaluation of residual stress alteration by grinding in case-carburised En36 steel, ActaMaterialia 53, 2005, 4997-5006.

8. Moorthy V., Vaidyanathan S., Jayakumar T., Raj B., B.P. Kashyap, Effect of tensile deformation on micromagnetic parameters in $0.2 \%$ carbon steel and $2.25 \mathrm{cr} \pm 1 \mathrm{mo}$ steel. ActaMaterialia, 47(6), 1999, 1869-1878.

9. L.P. Karjalainen and M. Moilanen and R.Rautioaho, Influence of tensile and cyclic loading upon Barkhausen noise in a mild steel, Mater. Eval. 37 (9), 1979, 45-51.

10. L. P. Karjalainen, and M. Moilanen, Fatigue softening and hardening in mild steel detected from Barkhausen Noise, IEEE Trans. on Magnetics, MAG-16 (3), 1980, 514517.

11. K. Tiitto, Use of Barkhausen noise in fatigue, Nondestr. Test. Eval. 5, 1989, 27-37.

12. Moorthy V., Choudhary B.K., Vaidyanathan S., Jayakumar T., BhanuSankaraRao K., Raj B., An assessment of low cycle fatigue damage using magnetic Barkhausen emission in 9Cr-1Mo ferritic steel. International Journal of Fatigue 21, 1999, 263-269

13. Dubois M., Fiset M., Evaluation of Case Depth on Steels by Barkhausen Noise Measurement, Materials Science and Technology, 11, 1995,264-267.

14. G. Bach, K. Goebbels and W.A. Theiner, Characterization of Hardening Depth using Barkhausen noise measurement, Mater. Eval. 46, 1988, 1576-1580.

15. S. Vaidyanathan, V. Moorthy, T. Jayakumar and Baldev Raj, 'Evaluation of induction hardened case depth through microstructural characterization using magnetic Barkhausen emission technique, Mater. Sci. and Tech., 16, 2000, 202-208.

16. V. Moorthy, B.A. Shaw, and K. Brimble, Testing of case depth in case-carburised gear steels using magnetic Barkhausen emission technique, Materials Evaluation, 62 (5) May 2004, 523-527. 
This article is author's version published in the Journal of Magnetism and Magnetic Materials, 345 (2013) 208-214. Final published version of this paper is available at

http://dx.doi.org/10.1016/j.jmmm.2013.06.038

\section{Black \& White Figures}

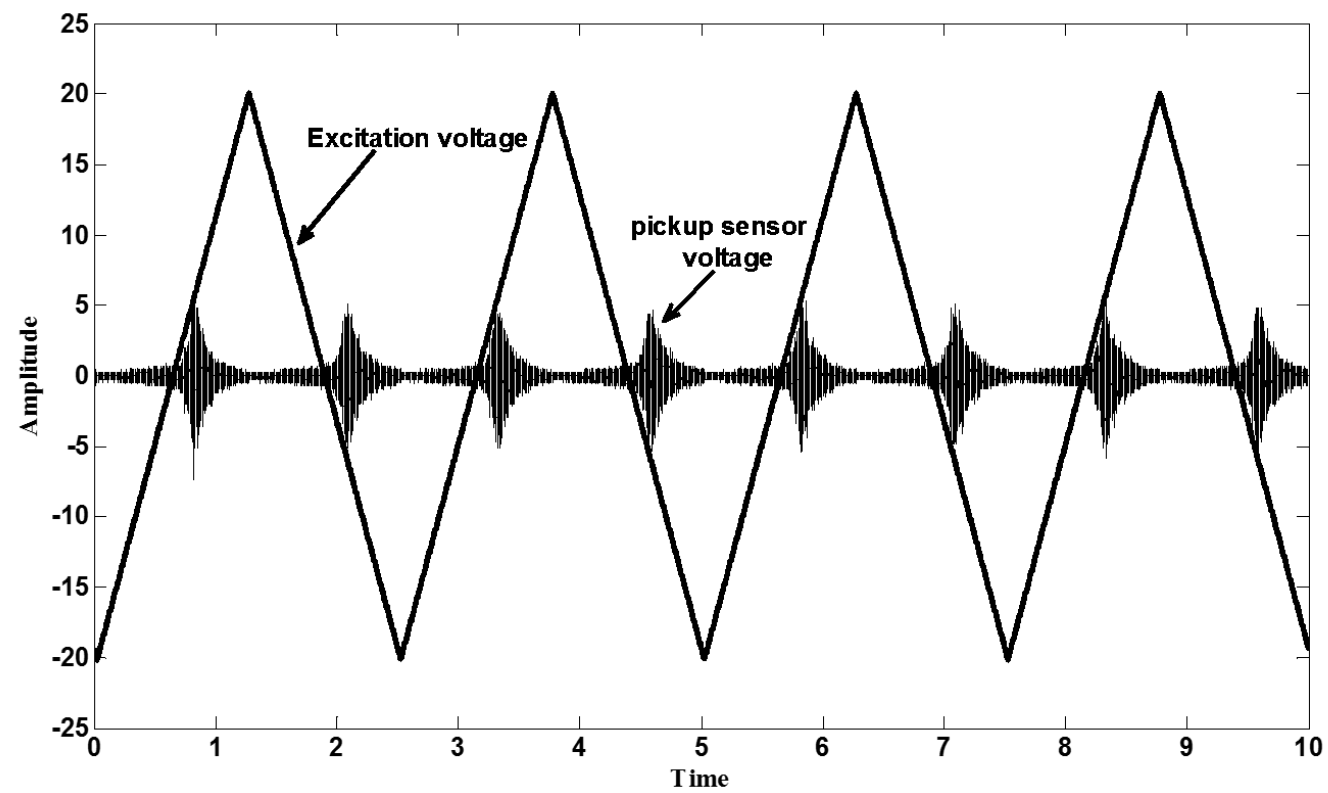

Fig.1. Typical excitation voltage and the MBN signals in time domain 
This article is author's version published in the Journal of Magnetism and Magnetic Materials, 345 (2013) 208-214. Final published version of this paper is available at

http://dx.doi.org/10.1016/j.jmmm.2013.06.038
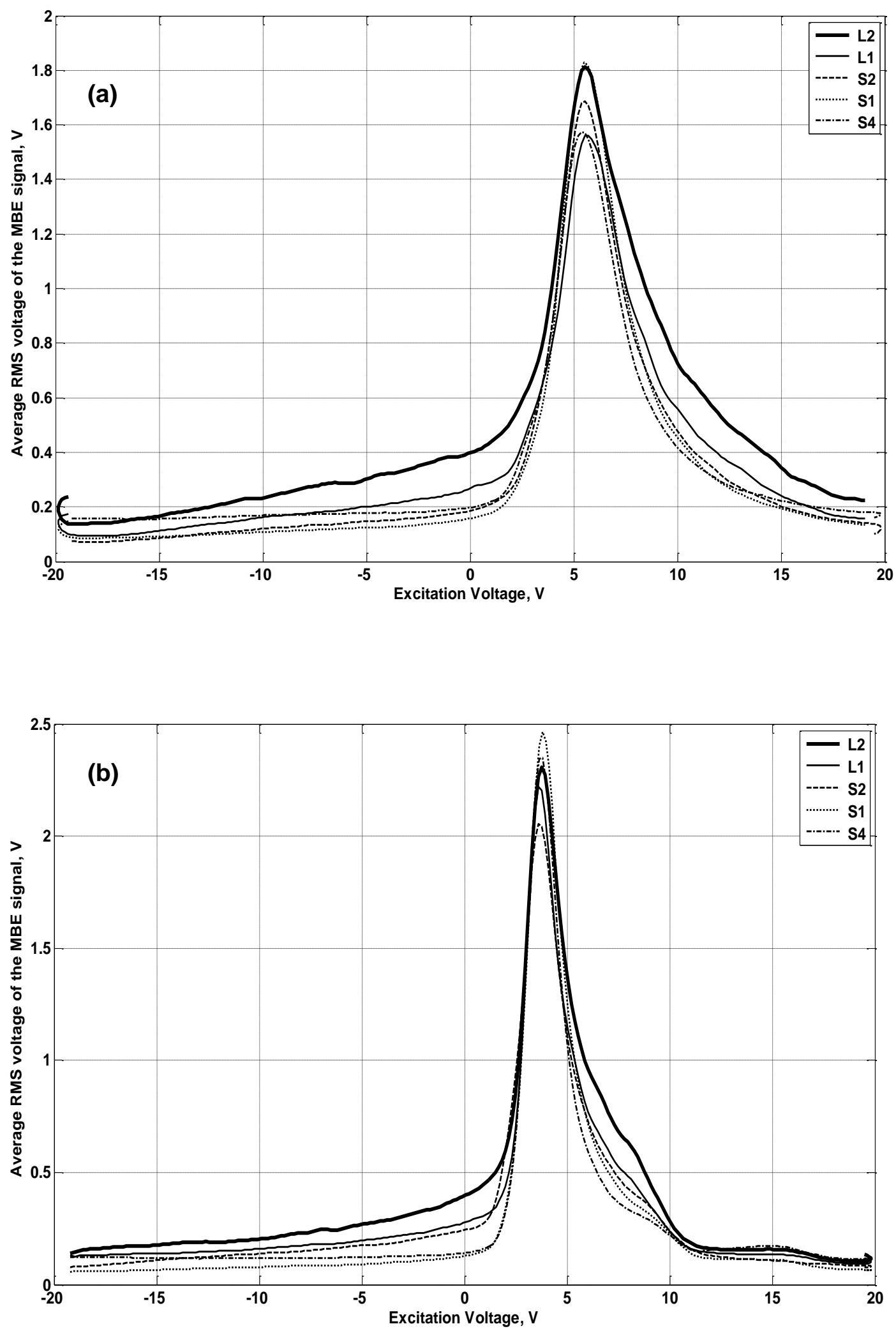

Fig.2. The low frequency MBN profiles obtained in quenched and tempered (QT) with different pick-up coils using electromagnetic yokes (a) Y1 and (b) Y2. 
This article is author's version published in the Journal of Magnetism and Magnetic Materials, 345 (2013) 208-214. Final published version of this paper is available at

http://dx.doi.org/10.1016/j.jmmm.2013.06.038
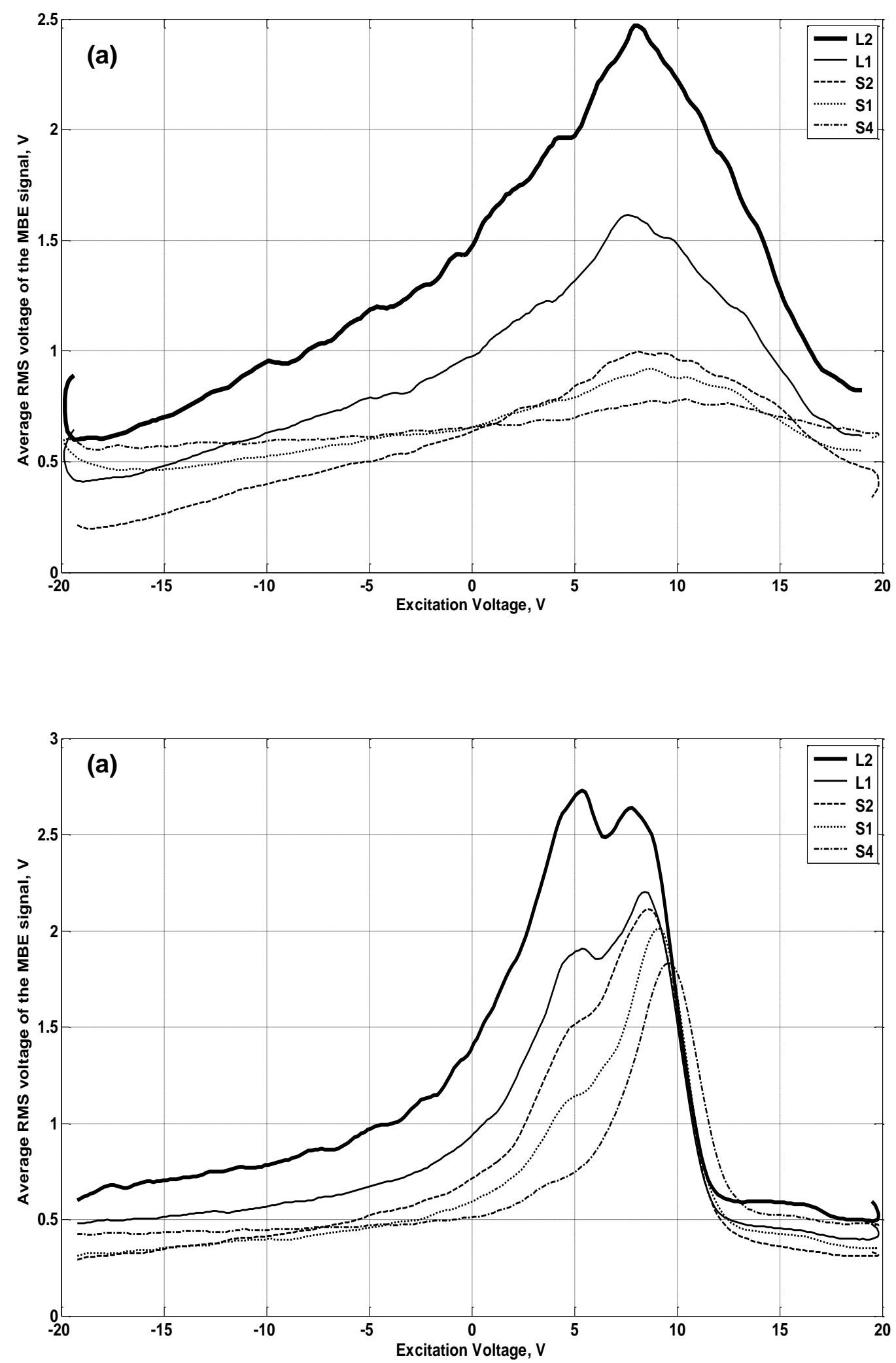

Fig.3. The low frequency MBN profiles obtained in carburised and tempered (CT) with different pick-up coils using electromagnetic yokes (a) Y1 and (b) Y2. 
This article is author's version published in the Journal of Magnetism and Magnetic Materials, 345 (2013) 208-214. Final published version of this paper is available at

http://dx.doi.org/10.1016/j.jmmm.2013.06.038
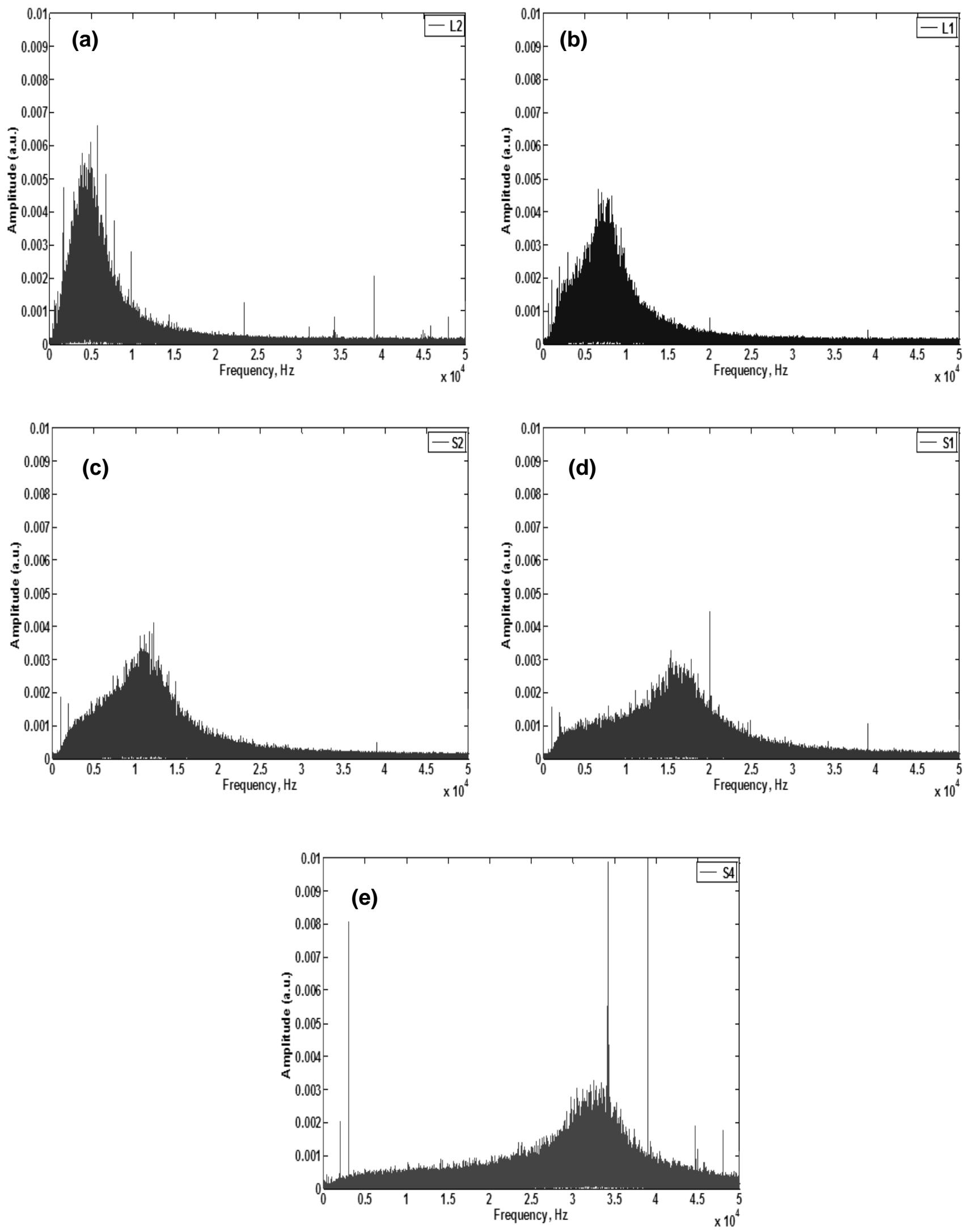

Fig. 4. Frequency spectra of MBN signals acquired using different pick-up coils in a quenched and tempered sample with electromagnetic yoke Y2. (a) L2, (b) L1, (c) S2, (d) S1 and (e) S4. 
This article is author's version published in the Journal of Magnetism and Magnetic Materials, 345 (2013) 208-214. Final published version of this paper is available at

http://dx.doi.org/10.1016/j.jmmm.2013.06.038
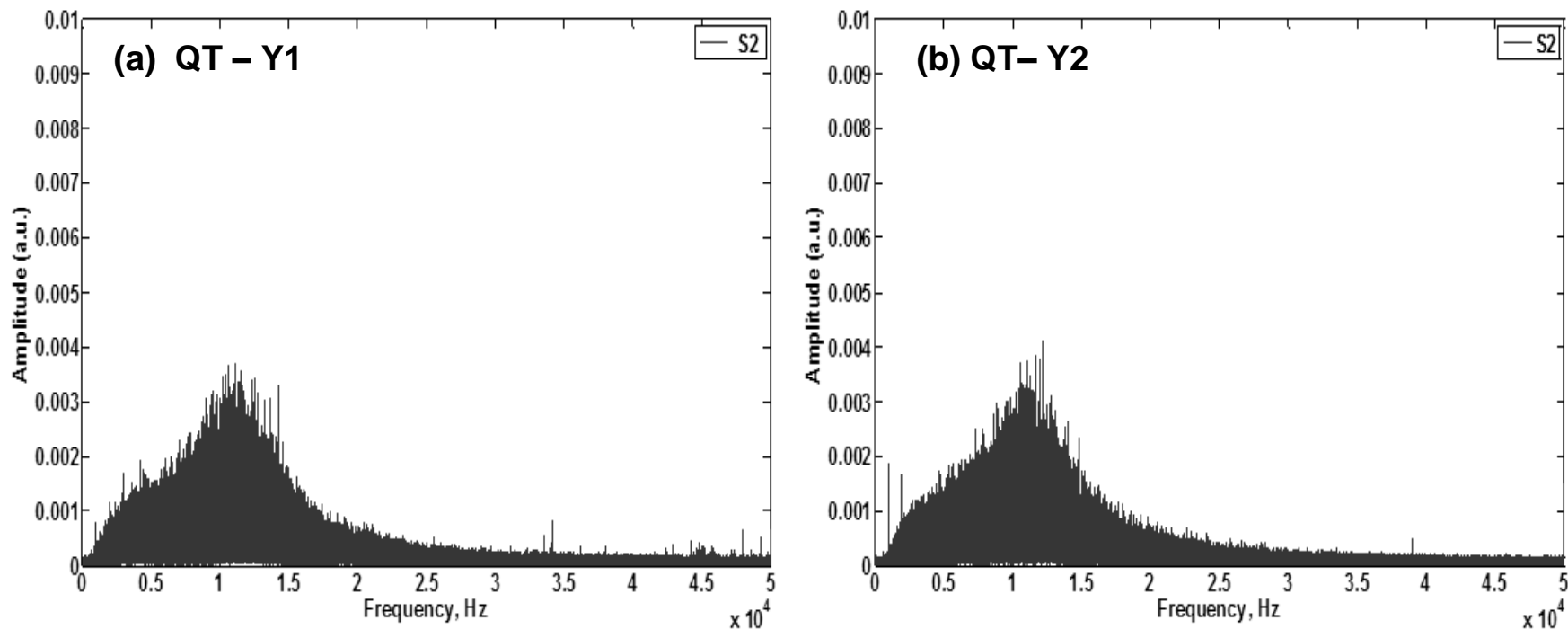

Fig. 5. Frequency spectra of MBN signals acquired using the pick-up coil $\mathrm{S} 2$ in a quenched and tempered sample with electromagnetic yokes (a) $\mathrm{Y} 1$ and (b) $\mathrm{Y} 2$.
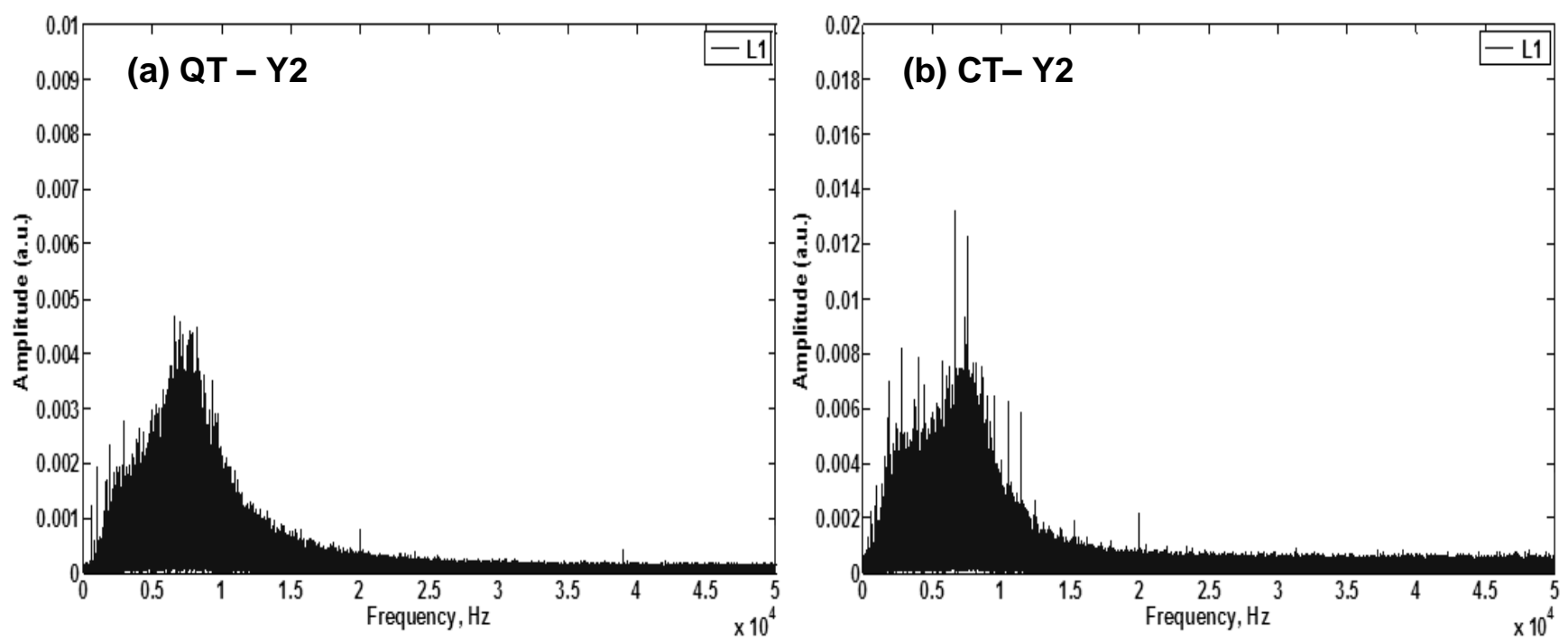

Fig.6. Frequency spectra of MBN signals acquired using pick-up coil L1 with electromagnetic yoke $Y 2$ in (a) quenched and tempered sample and (b) carburised and tempered sample. 
This article is author's version published in the Journal of Magnetism and Magnetic Materials, 345 (2013) 208-214. Final published version of this paper is available at

http://dx.doi.org/10.1016/j.jmmm.2013.06.038

\section{Colour Figures for on-line publication}

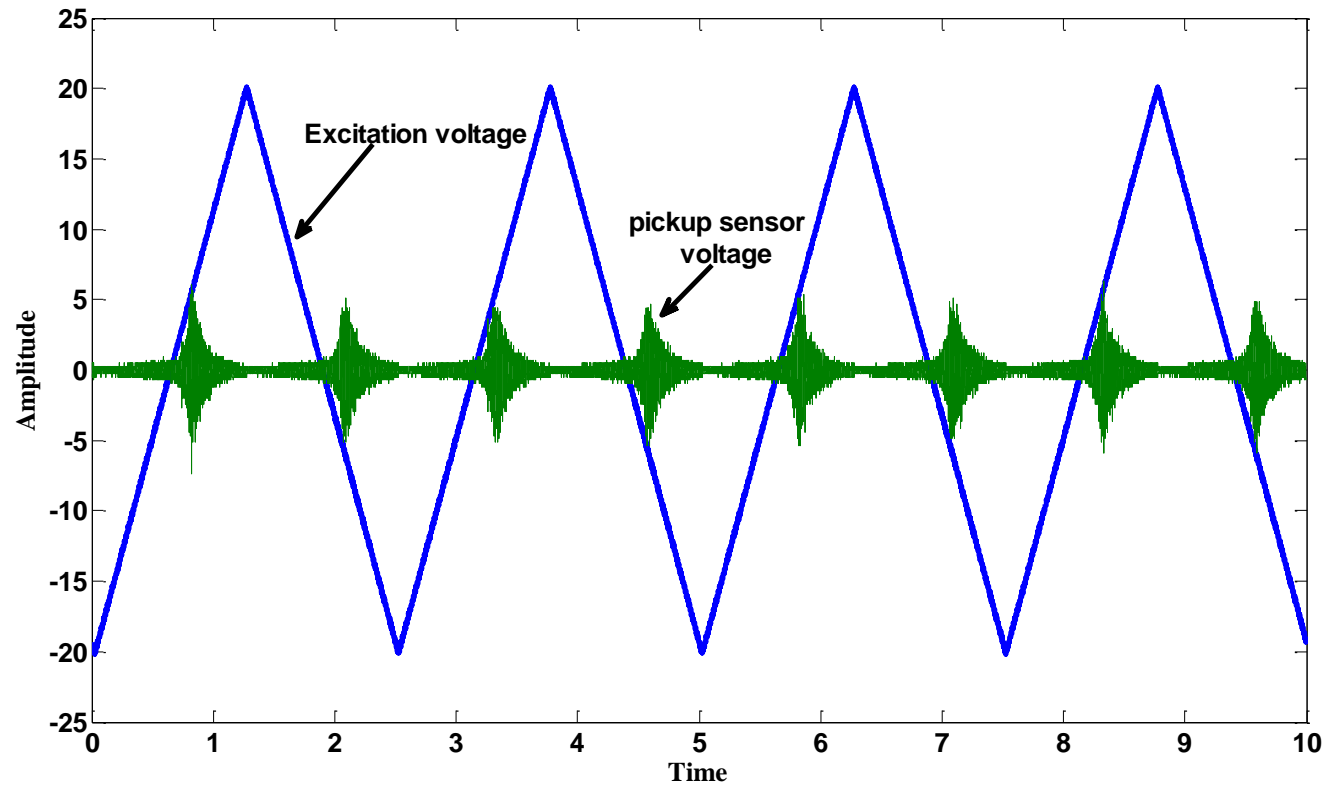

Fig.1. Typical excitation voltage and the MBN signals in time domain 
This article is author's version published in the Journal of Magnetism and Magnetic Materials, 345 (2013) 208-214. Final published version of this paper is available at

http://dx.doi.org/10.1016/j.jmmm.2013.06.038
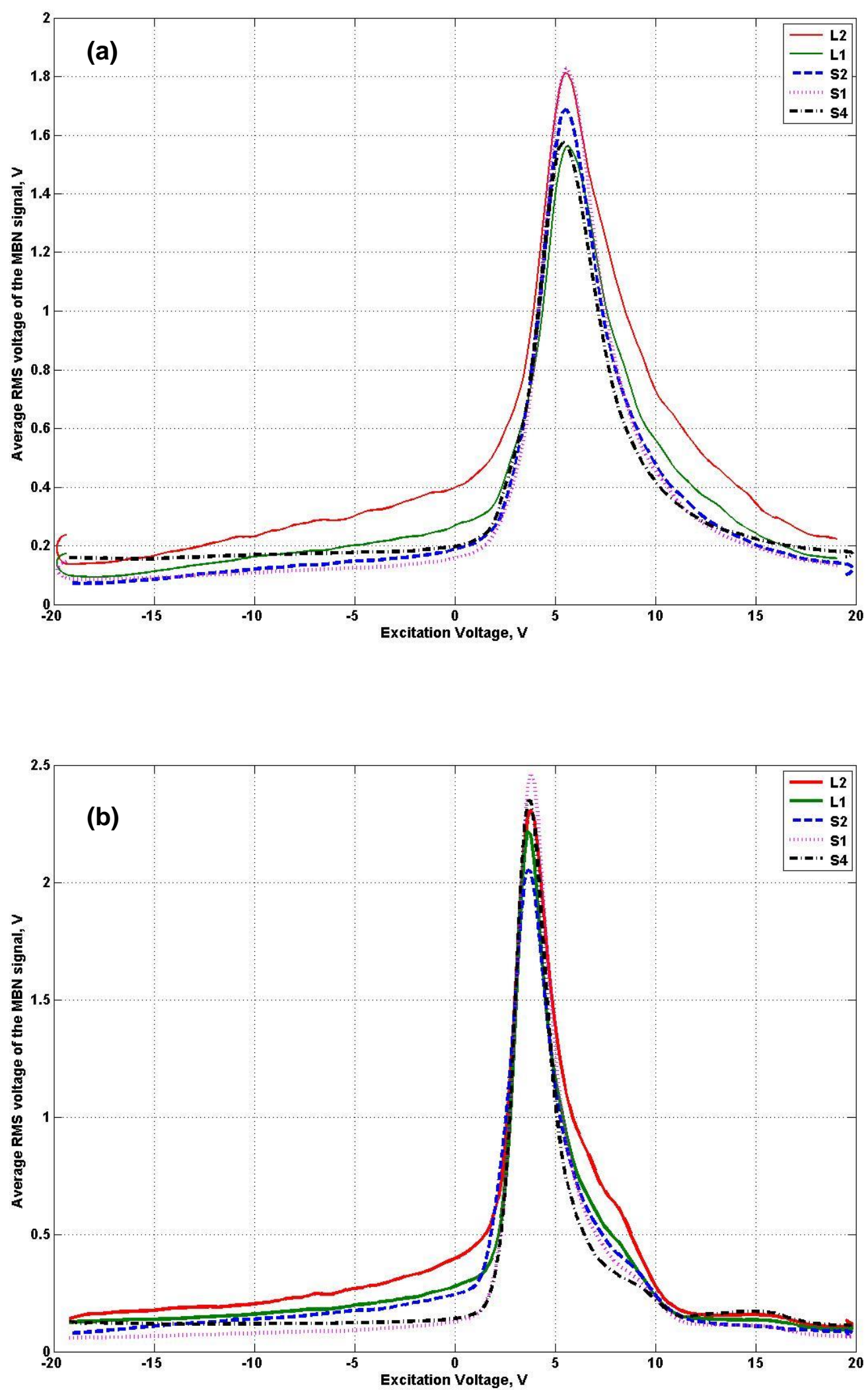

Fig.2. The low frequency MBN profiles obtained in quenched and tempered (QT)with different pick-up coils using electromagnetic yokes (a) Y1 and (b) Y2. 
This article is author's version published in the Journal of Magnetism and Magnetic Materials, 345 (2013) 208-214. Final published version of this paper is available at

http://dx.doi.org/10.1016/j.jmmm.2013.06.038
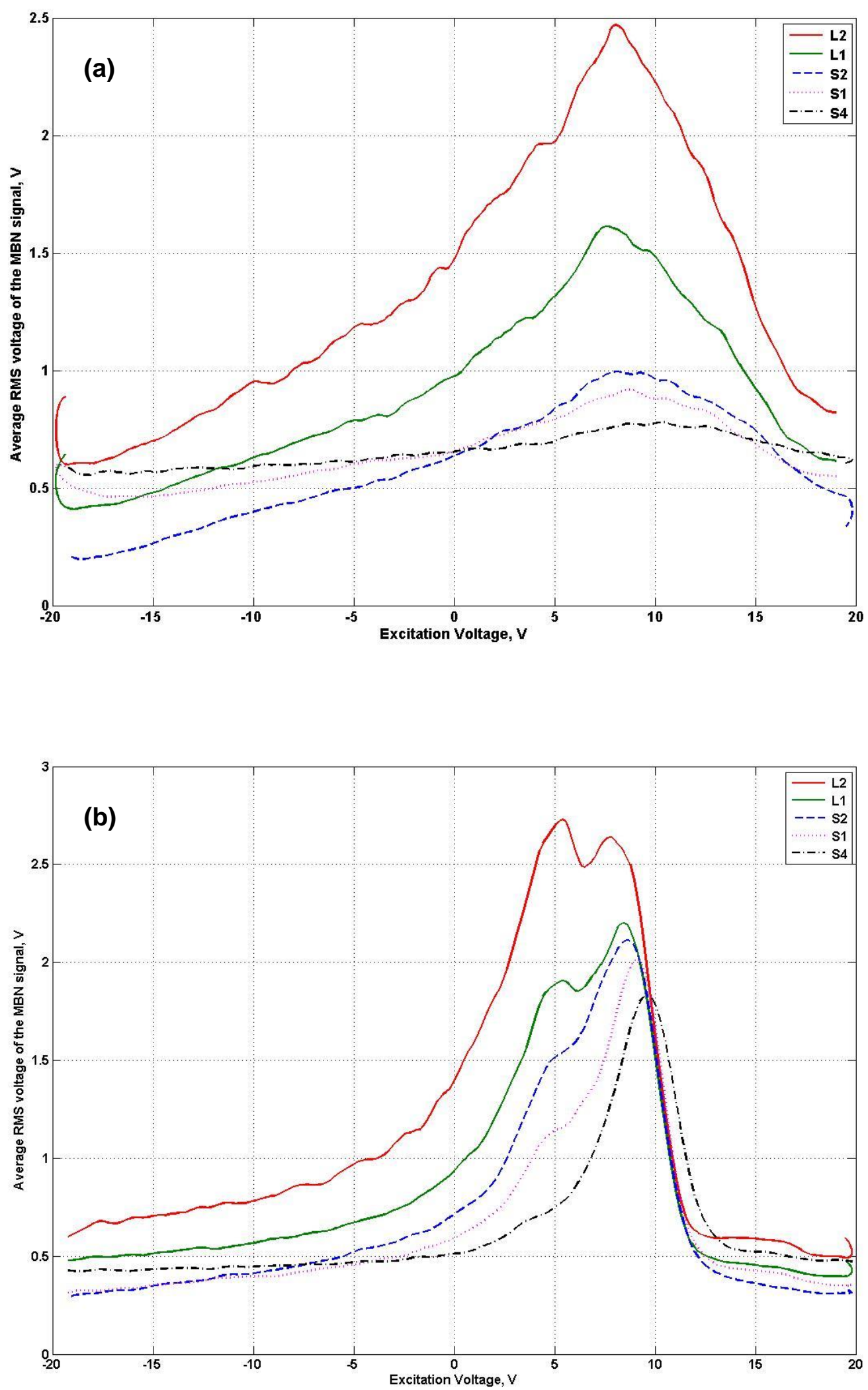

Fig.3. The low frequency MBN profiles obtained in carburised and tempered (CT) with different pick-up coils using electromagnetic yokes (a) Y1 and (b) Y2. 
This article is author's version published in the Journal of Magnetism and Magnetic Materials, 345 (2013) 208-214. Final published version of this paper is available at

http://dx.doi.org/10.1016/j.jmmm.2013.06.038
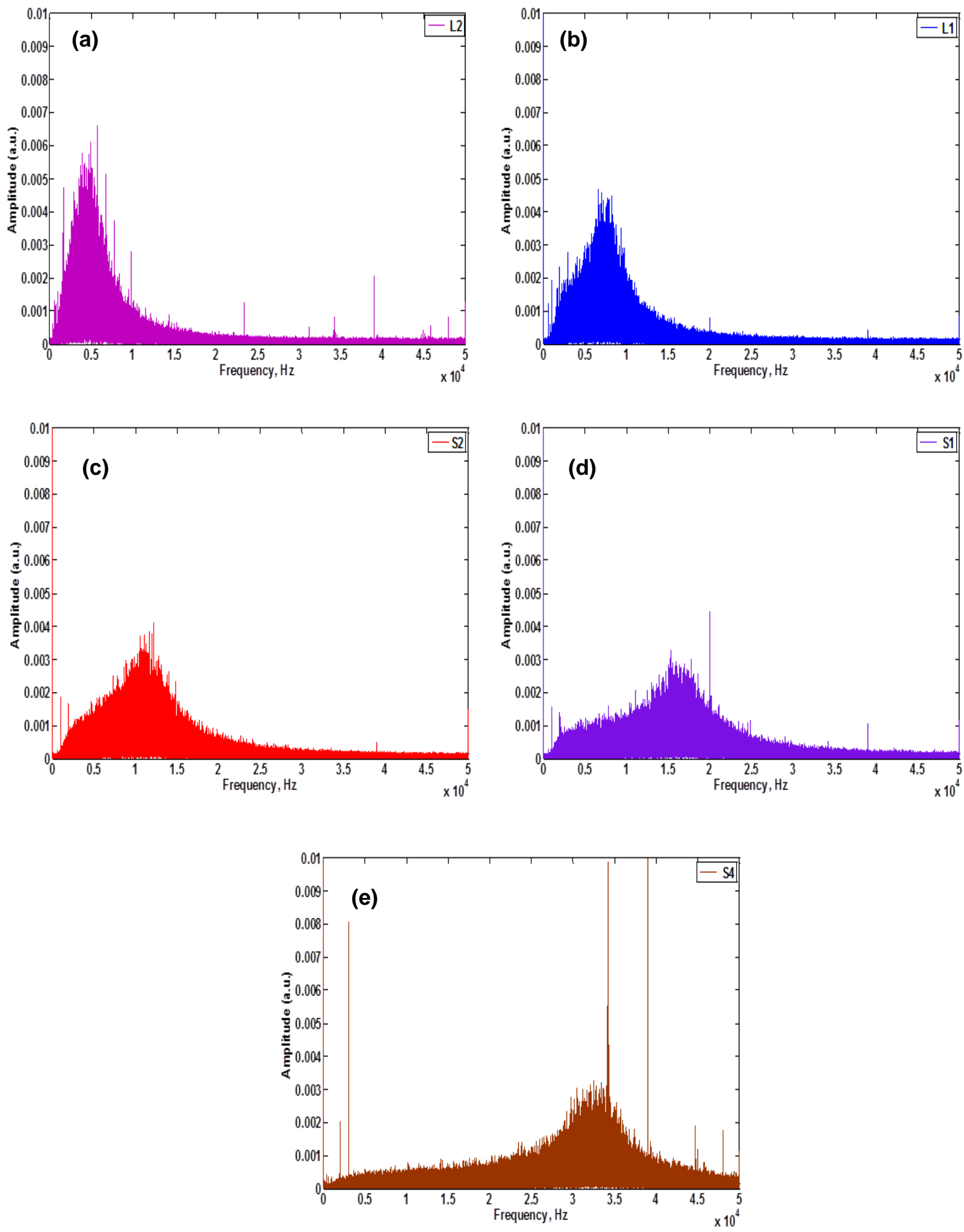

Fig. 4. Frequency spectra of MBN signals acquired using different pick-up coils in a quenched and tempered sample with electromagnetic yoke Y2. (a) L2, (b) L1, (c) S2, (d) S1 and (e) S4. 
This article is author's version published in the Journal of Magnetism and Magnetic Materials, 345 (2013) 208-214. Final published version of this paper is available at

http://dx.doi.org/10.1016/j.jmmm.2013.06.038
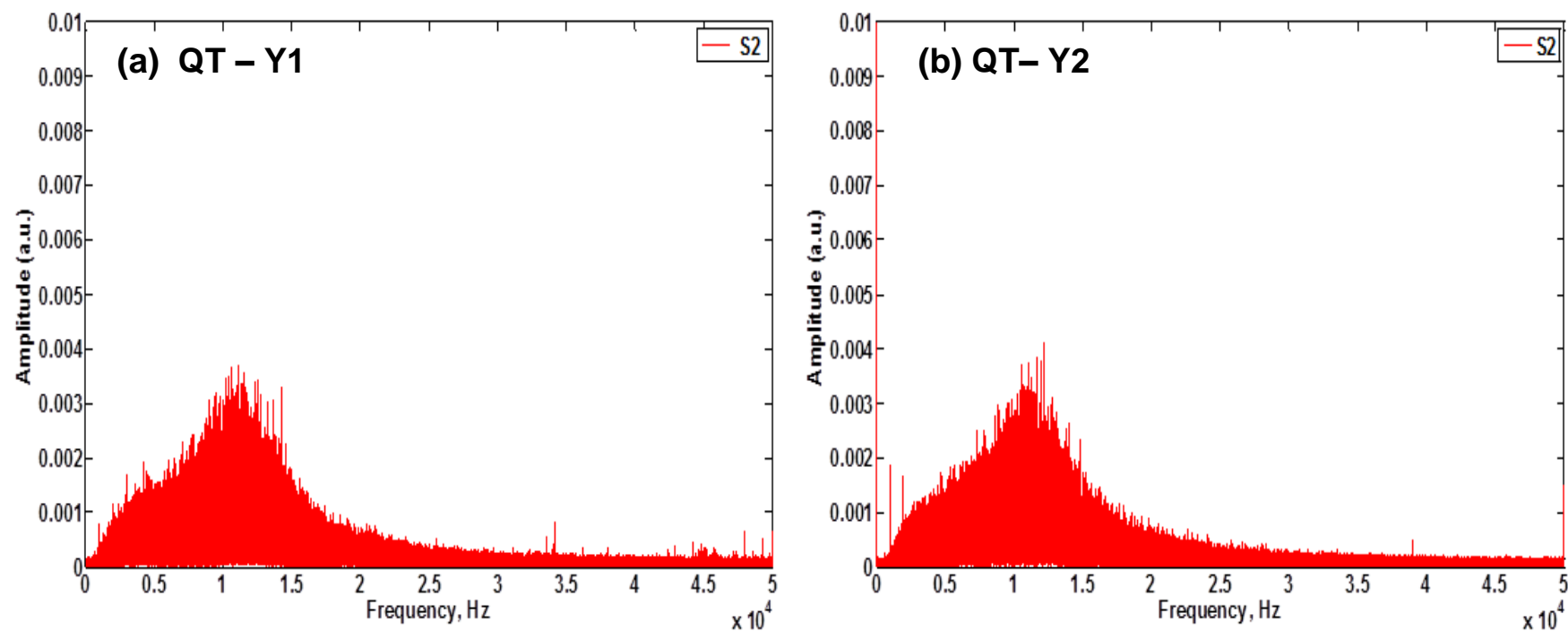

Fig. 5. Frequency spectra of MBN signals acquired using the pick-up coil $\mathrm{S} 2$ in a quenched and tempered sample with electromagnetic yokes (a) $\mathrm{Y} 1$ and (b) $\mathrm{Y} 2$.
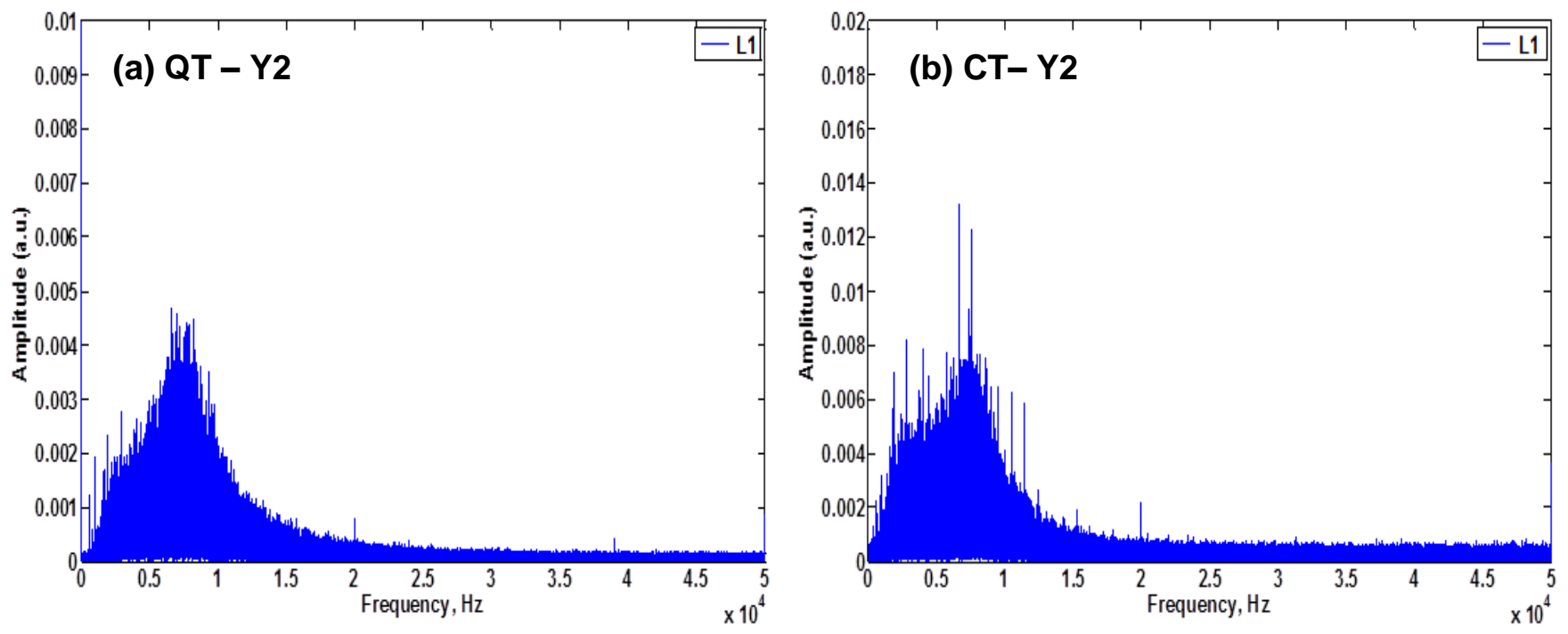

Fig.6. Frequency spectra of MBN signals acquired using pick-up coil L1 with electromagnetic yoke $\mathrm{Y} 2$ in (a) quenched and tempered sample and (b) carburised and tempered sample. 